\title{
Anti-Lithogenic Activity of Tetrapeptide Leu-Ile-Lys-His in Experimental Urolithiasis
}

\author{
N. N. Yakushev, $\mathrm{PhD}^{1}$; A. Yu. Zharikov, PhD, $\mathrm{ScD}^{1,2} ;$ O. N. Mazko, $\mathrm{PhD}^{1}$; \\ O. G. Makarova, $\mathrm{PhD}^{1}$; G. V. Zharikova ${ }^{1 *}$; V. M. Brukhanov, PhD, $\mathrm{ScD}^{1}$; Yu. V. Korenovsky, \\ $\mathrm{PhD}^{1}$; A. V. Lepilov, $\mathrm{PhD}, \mathrm{ScD}^{1}$; I. P. Bobrov, $\mathrm{PhD}, \mathrm{ScD}^{1}$; O. V. Azarova, $\mathrm{PhD}, \mathrm{ScD}^{1}$ \\ ${ }^{1}$ Altai State Medical University, Barnaul, Russia \\ ${ }^{2}$ Scientific-Research Institute of Physiology and Basic Medicine, Novosibirsk, Russia
}

\begin{abstract}
Background: The research objective was to study the effect of the tetrapeptide Leu-Ile-Lys-His on the course of experimental oxalate nephrolithiasis.

Methods and Results: Experiments were conducted on 30 male Wistar rats, which were divided equally into 3 groups: the control group ( 6 weeks of ON modeling), the test group ( 6 weeks of ON modeling+the tetrapeptide Leu-Ile-Lys-His introduction at a dose of $12 \mathrm{mg} / \mathrm{kg}$ ), and the experimental group (determination of indicators of free radical oxidation process activity in intact rats). Every 7 days, indicators of the excretory renal function (the level of diuresis and creatinine excretion) and activity of marker enzymes of renal tissue damage (lactate dehydrogenase and $\gamma$-glutamyl transferase) were determined in the urine of rats. After six weeks, we determined parameters of activity of the free radical oxidation process in the kidneys of rats posthumously and conducted the morphological study for formation of calcium deposits.

Conclusion: Experiments showed that in the control group there were characteristic signs of nephrolithiasis development: increase of LDH activity by 5.4 times, increase of free radical oxidation process activity in the kidneys, and formation of large concrements in the kidneys, the mean size of which was $298.8 \pm 34.2 \mu \mathrm{m}^{2}$. In the test group, there was weakening of LDH and GGT activity and weakening of free radical oxidation process activity. There were no morphological signs of nephrolithiasis development in the kidneys. (International Journal of Biomedicine. 2019;9(2):155-158.)
\end{abstract}

Key Words: oxalate nephrolithiasis $\bullet$ Leu-Ile-Lys-His tetrapeptide $•$ anti-lithogenic effect

\section{Introduction}

Previously, we found that the new pharmacological agent, the tetrapeptide Leu-Ile-Lys, showed pronounced antilithogenic activity in experimental oxalate nephrolithiasis. ${ }^{(1)}$ The obtained results are in good agreement with the so-called "proteomic approach" in the development of new methods of treatment for urolithiasis and create prerequisites for further search for new peptide molecules with potential anti-lithogenic activity.(2)

Today, there is information about the important role of histidine amino acid in the renal reabsorption of calcium. It has

*Corresponding author: Ganna V. Zharikova. Altai State Medical University, Barnaul, the Russian Federation. E-mail: anna1704@mail.ru been established that the activity of TRPV5 calcium channels in the kidneys, which are involved in the reverse absorption of calcium in distal tubules, is regulated by a histidine-kinase signal pathway, and that the presence of histidine in the carboxyl terminal of TRPV5 channels is required to activate these channels. ${ }^{(3)}$ It is possible that external modulation of this signal pathway can change the character of intrarenal calcium transport, and thus change the intensity of calcium concrements formation.

Taking into account the above, we decided to experimentally assess the impact of the new Leu-Ile-LysHis tetrapeptide on the processes of stone formation in experimental oxalate nephrolithiasis.

The research objective was to study the effect of the tetrapeptide Leu-Ile-Lys-His on the course of experimental oxalate nephrolithiasis 


\section{Materials and Methods}

The study was conducted on 30 male Wistar rats weighing $200-250 \mathrm{~g}$ that were on a standard laboratory diet. Animals were grown in the Department of Animal and Human Genetics of the Federal Research Center "Institute of Cytology and Genetics" of the Siberian branch of the Russian Academy of Sciences (Novosibirsk). The work with animals was carried out in accordance with the principles of humanism laid down in the directives of the European Community (86/609/EEC) and the Declaration of Helsinki, in accordance with the "Animal experimentation legislations". Throughout the experiment, animals were in individual metabolic cells adapted for urine collection, in conditions of free access to fluids and food under the natural light mode. All procedures with the animals, namely weighing, introduction of study objects, and euthanasia, were carried out in the interval of time from 9 a.m. to 12 noon.

Rats were divided equally into 3 groups: Group 1 $(\mathrm{n}=10)$ - the control group; Group $2(\mathrm{n}=10)$ - the test group; Group $3(\mathrm{n}=10)$ - the experimental group. In Groups 1 and 2, oxalate nephrolithiasis was modeled according to the generally accepted "ethylene glycol model."(4) The bottom line is that rats receive a $1 \%$ ethylene glycol (EG) solution for free drinking. In hepatocytes, under the influence of microsomal enzymes, EG metabolizes to an oxalate-ion, which is then excreted with urine where it reacts with calcium ions, forming insoluble crystals of cipitating calcium oxalate. Under these conditions, nephrolithiasis is considered to develop up to the end of the third week of modeling, acquiring a stable form in a period of 3-6 weeks. Therefore, the duration of pathology modeling was 6 weeks. In Group 2, the tetrapeptide LeuIle-Lys-His was administrated from day 22 to day 42 orally through a probe in the form of a starch suspension at a dose of $12 \mathrm{mg} / \mathrm{kg}$.

The tetrapeptide Leu-Ile-Lys-His was synthesized at the enterprise of SHANGHAI APEPTIDE CO., LTD (Shanghai, China), supported by "Evalar" ZAO (Biysk, Russia).

In Group 3, the indicators of free radical oxidation activity were measured in normal intact rats. In Groups 1 and 2 , daily urine volume was collected every week during the experiment, in which creatinine concentration and activity of marker enzymes of nephrothelium damage-lactate dehydrogenase (LDH) and $\gamma$-glutamyl transferase (GGT) were determined in order to assess the degree of renal tissue damage in ON modeling on the automatic biochemical analyzer DIRUI CS-T240. Creatinine concentration was determined by a kinetic method without deproteinization basing on the Jaffe reaction with formation of the red-orange colored complex. The principle of the method for determining $\mathrm{LDH}$ activity is based on the reaction of pyruvate recovery to lactic acid; the reaction rate is proportional to $\mathrm{LDH}$ activity in the sample. The determination of GGT activity is based on the reaction of transfer of L- $\gamma$-glutamyl-3-carboxy-p-nitroanilide to glycylglycine, which is catalyzed by this enzyme with the formation of the colored 5-amino-2-nitrobenzoate.

After 6 weeks of the experiment, the rats were euthanized under ethereal anesthesia and both kidneys were extracted, one of which was used to determine activity of the free radical oxidation process in the renal tissue, and the other one for morphological research.

The activity of the free radical oxidation process in the renal tissue was estimated by a combination of pro-oxidant and antioxidant indicators. The first ones included the content of thiobarbituric acid reactive products (TBARP) and the total pro-oxidant activity (TPA), the second ones - total antioxidant activity (TAA) and activity of antioxidant enzymes: glutathione peroxidase (GPx), superoxide dismutase (SOD), and catalase (CAT).

TBARP were determined by the colorimetric method for measuring the intensity of the coloring solution during the chemical reaction of TBRP with TBA. TPA was estimated by accumulation of Tween 80 peroxidation products reacting with TBA. TAA was assessed as an integrative activity indicator of all enzymatic and nonenzymatic factors of neutralization of free radicals by degree of oppression of $\mathrm{Fe}^{2+} /$ Tween- 80 ascorbatedependent oxidation by tissue homogenate. To determine the glutathione peroxidase (GPx) activity, the concentration of reduced glutathione was measured in a colored reaction with Ellman's reagent. The SOD activity was determined by suppressing the formation of nitro formazan, which is a colored product of nitrotetrazolium oxidation by superoxide radicals formed by interaction of phenazinmetasulfate and nicotinamidinucleotide (NADN). The CAT activity was determined by suppressing sodium molybdate with the oxidation enzyme of hydrogen peroxide.

For morphological studies, the kidneys were fixed in $10 \%$ formalin solution, treated according to the standard method, and a cross section $6 \mu \mathrm{m}$ thick was produced through the renal papilla. The resulting sections were colored with H\&E, methenamine-silver. Calcium deposits were identified by the von Kossa staining method. The number of calcium deposits pictured in the field of vision and their sizes were determined using a computer program. Morphometric studies were carried out using the ImageJ 1.43 and AxioVision 3.1 software packages.

Statistical analysis was performed using StatSoft Statistica v12.0. The results of biochemical studies are presented as the median (Me) and interquartile range (IQR; 25 th to 75 th percentiles). The results of morphometric studies are presented as the mean (M) and standard error of the mean (SEM). Statistical comparisons between groups were performed using the non-parametric Kruskal-Wallis test and Mann-Whitney U-test; comparisons within groups with respect to the reference level were made using the nonparametric Wilcoxon test. A probability value of $P<0.05$ was considered statistically significant.

\section{Results}

Conducted experiments showed that in rats of Group 1 there were characteristic signs of nephrolithiasis development. First, the activity of marker enzymes of renal epithelium damage increased (Table 1). The LDH activity increased 5.4 times during the experiment $(P=0.012)$. The study of free radical oxidation process activity in the kidneys of rats 
in Group 1 showed (Table 2) that the TBARP concentration increased 1.2 times compared to the level of intact rats of Group $3(P=0.004)$. In addition, TAA decreased 3.5 times and SOD activity increased 1.4 times $(P=0.0002)$.

\section{Table 1.}

Indicators of lactate dehydrogenase and $\gamma$-glutamyl transferase activity in the study of Leu-Ile-Lys-His peptide impact on the course of experimental oxalate nephrolithiasis

\begin{tabular}{|c|c|c|c|c|}
\hline & \multicolumn{2}{|c|}{$\begin{array}{c}\mathrm{LDH} \\
\text { (U/mg of creatinine per day) }\end{array}$} & \multicolumn{2}{|c|}{$\begin{array}{c}\text { GGT } \\
\text { (U/mg of creatinine per day) }\end{array}$} \\
\hline & Group 1 & Group 2 & Group 1 & Group 2 \\
\hline $\begin{array}{l}\text { Initial } \\
\text { level }\end{array}$ & $\begin{array}{c}0.09 \\
(0.06 ; 0.15)\end{array}$ & $\begin{array}{c}0.21 \\
(0.18 ; 0.39) \\
P_{\mathrm{c}}=0.061\end{array}$ & $\begin{array}{c}0.74 \\
(0.56 ; 1.06)\end{array}$ & $\begin{array}{c}0.93 \\
(0.48 ; 1.41) \\
P_{\mathrm{c}}=0.747\end{array}$ \\
\hline Week 1 & $\begin{array}{c}0.11 \\
(0.07 ; 0.28)\end{array}$ & $\begin{array}{c}0.13 \\
(0.07 ; 0.37) \\
P_{\mathrm{c}}=0.452\end{array}$ & $\begin{array}{c}0.74 \\
(0.68 ; 1.03)\end{array}$ & $\begin{array}{c}0.87 \\
(0.54 ; 1.00) \\
P_{\mathrm{c}}=0.875\end{array}$ \\
\hline Week 2 & $\begin{array}{c}0.22 \\
(0.15 ; 0.33)\end{array}$ & $\begin{array}{c}0.16 \\
(0.12 ; 0.19) \\
P_{\mathrm{c}}=0.333\end{array}$ & - & - \\
\hline Week 3 & - & - & - & - \\
\hline Week 4 & $\begin{array}{c}0.22 \\
(0.13 ; 0.37)\end{array}$ & $\begin{array}{c}0.23 \\
(0.08 ; 0.37) \\
P_{\mathrm{c}}=0.793\end{array}$ & $\begin{array}{c}0.74 \\
(0.59 ; 1.29)\end{array}$ & $\begin{array}{c}0.73 \\
(0.35 ; 1.23) \\
P_{\mathrm{c}}=0.875\end{array}$ \\
\hline Week 5 & $\begin{array}{c}0.42 \\
(0.34 ; 0.55) \\
P_{\text {in }}=0.012\end{array}$ & $\begin{array}{c}0.12 \\
(0.03 ; 0.20) \\
P_{\mathrm{c}}=0.002\end{array}$ & $\begin{array}{c}1.22 \\
(0.55 ; 1.88)\end{array}$ & $\begin{array}{c}0.33 \\
(0.25 ; 0.36) \\
P_{\text {in }}=0.028 \\
P_{\mathrm{c}}^{=}=0.0004\end{array}$ \\
\hline Week 6 & $\begin{array}{c}0.49 \\
(0.18 ; 0.60) \\
P_{\text {in }}=0.012\end{array}$ & $\begin{array}{c}0.03 \\
(0.02 ; 0.05) \\
P_{\text {in }}=0.028 \\
P_{\mathrm{c}}^{=}=0.0006\end{array}$ & $\begin{array}{c}0.85 \\
(0.49 ; 2.37)\end{array}$ & $\begin{array}{c}0.13 \\
(0.08 ; 0.18) \\
P_{\mathrm{n}}=0.028 \\
P_{\mathrm{c}}=0.001\end{array}$ \\
\hline
\end{tabular}

$P_{n}$ - level of statistical significance of differences in comparison with the initial level of the corresponding indicator; $P_{\text {c }}$ - level of statistical significance of changes of the corresponding indicator in Group 2 ( the test group) in comparison with Group 1 (the control group).

The morphological study of the kidneys of rats in Group 1 showed that when coloring with H\&E on nephrolithiasis areas, tubular epithelium was in a state of hyaline-drop dystrophy. The apical edge of cells was destroyed in some places; the brush border was not visible in some places. The tubules looked cystic stretched at the same time. Nephrothelium cells covering the tubules were either destroyed, flattened or atrophic.
We determined that there was weak or moderate inflammatory lymphoplasmacytic infiltration around the tubules, and noted nephrosclerosis phenomena. The vessels were in a state of pronounced hyperemia.

During the histochemical coloring for calcium by von Kossa's staining method, we observed that the stone deposit crystals in singles or in groups were of brownish-black color and of various shapes and sizes in the tubules of the kidneys of rats in the control group. The number of deposits in channel lumens ranges from 6 to 19 and averaged $7.9 \pm 1.6$ in the field of vision with an increase $\times 400$ with a modal value of 6 . When conducting computer morphometry, the area of stone deposits ranged from $48.8 \mu \mathrm{m}^{2}$ to $789.9 \mu \mathrm{m}^{2}$, with an average of $298.8 \pm 34.2 \mu \mathrm{m}^{2}$. A more detailed analysis of the distribution of stones depending on their area revealed that the number of stone deposits from $20 \mu \mathrm{m}^{2}$ to $100 \mu \mathrm{m}^{2}$ amounted to $16.7 \%$, the number of deposits from $100 \mu \mathrm{m}^{2}$ to $300 \mu \mathrm{m}^{2}$ amounted to $47.2 \%$, and the content of deposits over $300 \mu \mathrm{m}^{2}$ amounted to $36.1 \%$.

Against this background, in the long-term use of the tetrapeptide Leu-Ile-Lys-His or the correction of modeled nephrolithiasis, significant differences in the pattern of pathology were observed, compared to the control group. It turned out that since Week 5 of the experiment, LDH activity decreased and statistically significantly differed from the same indicator of Group 1: in Week 5, it was 3.5 times less ( $P=0.002)$, in Week $6-16.3$ times less $(P=0.0006)$. By the end of Week 6, LDH activity was even 7 times less than its initial level $(P=0.028)$.

On the whole, the same dynamics characterized the changes in GGT activity in Group 2. It turned out that in Week 5 and Week 6, it significantly decreased, compared to the initial level: 2.8 times and 7.2 times, respectively $(P=0.028)$. However, it was statistically significantly less than in Group 1 in the same period of time: in Week $5-3.7$ times $(P=0.0004)$, and in Week $6-6.5$ times $(P=0.001)$.

The study of the activity of free radical oxidation process in the kidneys of rats in Group 2 revealed that after a 3-week application of the tetrapeptide Leu-Ile-Lys-His, TPA decreased 7 times, compared to Group 1 (Table 2). At the same time, TAA significantly increased: 4.7 times compared to the level of Group $1(P=0.0002)$ and 1.3 times compared to intact rats of Group $3(P=0.0002)$. In addition, GPx activity increased 1.4 times compared to Group $1(P=0.0000)$ and 1.6 times compared to Group $3(P=0.0000)$.

Table 2.

Indicators of free radical oxidation process activity in the kidneys of experimental rats

\begin{tabular}{|l|c|c|c|c|c|c|}
\hline \multicolumn{1}{|c|}{ Group } & $\begin{array}{c}\text { TBRP } \\
(\mu \mathrm{mol} / \mathrm{mg})\end{array}$ & $\begin{array}{c}\text { TPA } \\
(\%)\end{array}$ & $\begin{array}{c}\text { TAA } \\
(\%)\end{array}$ & $\begin{array}{c}\text { GPx } \\
(\%)\end{array}$ & $\begin{array}{c}\text { CAT } \\
(\%)\end{array}$ & $\begin{array}{c}\text { SOD } \\
(\%)\end{array}$ \\
\hline $\begin{array}{l}\text { Group 3 } \\
\text { (Experimental) }\end{array}$ & $6.1(5.4 ; 6.9)$ & $65.1(63.4 ; 68.0)$ & $41.7(40.2 ; 43.3)$ & $38.5(25.2 ; 41.6)$ & $14.4(10.2 ; 15.6)$ & $18.2(13.0 ; 18.5)$ \\
\hline $\begin{array}{l}\text { Group 1 } \\
\text { (Control) }\end{array}$ & $\begin{array}{c}7.6(7.2 ; 7.6) \\
P_{\text {in }}=0.004\end{array}$ & $\begin{array}{c}54.0(49.9 ; 56.8) \\
P_{\mathrm{n}}=0.0002\end{array}$ & $\begin{array}{c}12.0(10.4 ; 13.2) \\
P_{\text {in }}=0.0002\end{array}$ & $42.2(32.2 ; 47.9)$ & $12.2(9.0 ; 15.8)$ & $\begin{array}{c}25.1(23.6 ; 32.1) \\
P_{\text {in }}=0.0002\end{array}$ \\
\hline $\begin{array}{l}\text { Group 2 } \\
\text { (Test) }\end{array}$ & $7.5(6.1 ; 10.7)$ & $\begin{array}{c}7.7(5.0 ; 13.3) \\
P_{\mathrm{n}}=0.0002 \\
P_{\mathrm{c}}=0.0002\end{array}$ & $\begin{array}{c}56.1(53.9 ; 58.9) \\
P_{\mathrm{in}}=0.0002 \\
P_{\mathrm{c}}=0.0002\end{array}$ & $\begin{array}{c}59.8(58.3 ; 66.4) \\
P_{\mathrm{in}}=0.0000 \\
P_{\mathrm{c}}=0.0000\end{array}$ & $13.8(10.5 ; 24.7)$ & $\begin{array}{c}6.5(3.5 ; 10.7) \\
P_{\text {in }}=0.002 \\
P_{\mathrm{c}}=0.0002\end{array}$ \\
\hline
\end{tabular}

$P_{i n}$ - level of statistical significance in comparison with Group 3; $P_{c}$ - level of statistical significance in comparison with Group 1. 
Finally, there was a decrease in SOD activity 3.9 times compared to Group $1(P=0.0002)$, resulting in this indicator being even 2.8 times less than the level of intact rats $(P=0.002)$.

The morphological study of the kidneys of rats in Group 2 showed that no nephrolithiasis phenomena were detected in this group. Renal tissues were in a normal state; neither inlay of tubules with calcium salts nor formation of large concrements was observed.

\section{Discussion}

Thus, the conducted experiments allowed us to determine high anti-lithogenic activity of the tetrapeptide Leu-Ile-Lys-His. It emerged that no morphological signs of nephrolithiasis development were revealed in the group where Leu-Ile-Lys-His was introduced. At the same time, oxidative stress in the renal tissue was weakening and LDH and GGT activity was decreasing against the background of treatment, which indicates normalization of the structure and function of urothelium.

The mechanisms of the identified anti-lithogenic effect have yet to be studied. However, there are data in the available literature that can clarify, to some extent, the ability of histidine-containing oligopeptides to weaken the formation of stones. For example, it is known that endogenous dipeptide carnosine ( $\beta$-alanyl-L-histidine) plays a significant role in renal pathologies. ${ }^{(5,6)}$ In particular, it reduces the synthesis of matrix products in the kidneys, such as fibronectin and type VI collagen. In this context, it is worth mentioning that a number of matrix large-molecular glycoproteins are powerful stimulants of crystallization in the kidneys. ${ }^{(7)}$ In addition, carnosine is able to reduce the level of pro-inflammatory cytokines. It is well known that inflammatory processes in tubules largely determine the formation of the primary focus of lithogenesis. ${ }^{(8)}$

Is it possible that the Leu-Ile-Lys-His tetrapeptide we developed and studied has activity in the kidneys similar to that of carnosine, which contributes to the inhibition of stone formation. Of course, such assumptions require further in-depth study. However, the obtained results show for the first time the anti-lithogenic activity of histidine-containing tetrapeptide.

\section{Conclusion}

In experimental oxalate nephrolithiasis, the 3 -week application of Leu-Ile-Lys-His was accompanied by a pronounced anti-lithogenic effect. There was a decrease in the activity of marker enzymes of renal epithelium damage and weakening of oxidative stress in the kidneys. No morphological signs of nephrolithiasis development were detected.

\section{Competing Interests}

The authors declare that they have no competing interests.

\section{References}

1. Zharikov AYu, Yakushev NN, Zharikova GV. Pharmacological agent for treatment of kidney stone disease. RU Patent (RU \#2679120; priority of 29.10.2018).

2. Mittal A, Tandon S, Singla S.K, Tandon C. Mechanistic Insights into the Antilithiatic Proteins from Terminalia arjuna: Proteomic Approach in Urolithiasis. PLoS One. 2016;11(9):e0162600. doi: 10.1371/journal.pone.0162600.

3. Cai X, Srivastava S, Surindran S, Li Z, Skolnik EY. Regulation of the epithelial $\mathrm{Ca}^{2+}$ channel TRPV5 by reversible histidine phosphorylation mediated by NDPK-B and PHPT1. Mol Biol Cell. 2014;25(8):1244-50. doi: 10.1091/mbc.E1304-0180.

4. Zharikov AYu, Brukhanov VM, Zverev YaF, Lampatov VV. [Current methods of modeling of oxalate nephrolythiasis]. Nephrology. 2008;12(4):28-35.[Article in Russian].

5. Kiliś-Pstrusińska K. [Carnosine, carnosinase and kidney diseases]. Postepy Hig Med Dosw (Online) 2012;66:215-21. [Article in Polish].

6. Peters V, Klessens CQ, Baelde HJ, Singler B, Veraar KA, Zutinic A, et al. Intrinsic carnosine metabolism in the human kidney. Amino Acids. 2015;47(12):2541-50. doi: 10.1007/ s00726-015-2045-7.

7. Zharikov AYu, Zverev YaF, Brukhanov VM, Lampatov VV. [The current conceptions about the modulators of the oxalate nephrolythiasis. I. stimulators of crystallization]. Nephrology. 2009;13(1):56-72. [Article in Russian].

8. Zharikov AYu, Zverev YaF, Brukhanov VM, Lampatov V.V. [Mechanism of formation of crystals in oxalate nephrolithiasis]. Nephrology. 2009;13(4):37-50. [Article in Russian]. 